\title{
THE ROLE OF ART IN ENVIRONMENTAL EDUCATION
}

\section{Vasileios Papavasileiou ${ }^{{ }^{*}}$, Eleni Nikolaou ${ }^{2}$, Nikos Andreadakis ${ }^{3}$, Yota Xanthacou ${ }^{4}$, Maria Kaila ${ }^{5}$}

\author{
${ }^{1}$ Assoc. Prof. Dr., University of the Aegean, Greece, vpapavasileiou@rhodes.aegean.gr \\ ${ }^{2}$ Assist. Prof. Dr., University of the Aegean, Greece, enikolaou@rhodes.aegean.gr \\ ${ }^{3}$ Assoc. Prof. Dr., University of the Aegean, Greece, nandread@rhodes.aegean.gr \\ ${ }^{4}$ Prof. Dr., University of the Aegean, Greece, xanthakou@rhodes.aegean.gr \\ ${ }^{5}$ Prof. Dr., University of the Aegean, Greece, kaila@rhodes.aegean.gr \\ ${ }^{*}$ Corresponding Author
}

\begin{abstract}
This paper examines the role of art in environmental education. It explores the creative use of fine arts for students' environmental awareness. The literature review carried out shows that artistic creation, in all its forms, painting, sculpture, architecture, music, dance, literature, theater, cinema, photography, comics can activate the senses, stimulates and enrich students' experiences, develops their imagination and critical thinking, provides new ways of expressing emotions, perceptions and reflections, enhances their creativity and develops their creative thinking. The pedagogical use of art in educational programs for enhancing children's contact with the environment helps children deepen their knowledge and strengthen their relationship with it. Art substantially contributes to environmental awareness, as it cultivates through an emotional approach the familiarization and the development of a connection with the environment. Therefore, educational planning is of scientific interest, which includes the utilization of various forms of artistic expression with the assistance of creative pedagogical techniques for the formation of active citizens.
\end{abstract}

Keywords: art, environmental education, environmental awareness, educational planning

\section{INTRODUCTION}

The role of art is considered particularly important for students' environmental awareness (Boeckel, 2009). The need to encourage children to develop an emotional connection with nature as a prerequisite for being aware of environmental issues and the development of responsibility towards the environment has been particularly emphasized. The development of the relationship with the environment includes not only knowledge but also emotion. The knowledge-based approach cannot influence deep-rooted values that motivate the individual to change his/her behavior.

Artistic and creative activities are important tools that facilitate the emotional connection between people and places. The arts can contribute to the emotional engagement with the natural environment and its protection (Wilson, 2011). Creative writing, literature, music, painting, photography, dramatization, cinema, etc., if utilized creatively in environmental education can significantly contribute to achieving environmental goals (Guveritz, 2000). 
Creative approaches can encourage children to explore and reflect on their values and their relationship to the environment. This approach aims to motivate the senses and seek for creative and innovative ways to deal with real issues. Adults who are environmentally aware recall scenes from the environment from their childhood experiences in the natural environment (Wilson, 2011).

A key point of environmental education through art is the provision of interactive experiences and the adoption of creative processes to connect children with the natural environment. It also includes creative approaches to problem solving and critical thinking development (Wilson, 2013).

The effectiveness of art experiences that contribute to the understanding of information about the natural environment is highlighted and emphasis is placed on participation as opposed to passive observation to maximize learning and comprehension. Simultaneously, the emotional connection that emerges through the charm, awe and admiration that children often experience when they come in contact with nature, and express them through art, is emphasized. Cognitive, emotional, and kinesthetic modes of knowledge are involved that can influence the development of cultural norms (Wilson, 2007; 2013).

Art is a source of inspiration and creation. People have always been looking for artistic expression to find meaning in their lives and to articulate their experiences. It is a vehicle for expressing fantasy. Simultaneously, it provides the means for communication through common representations and unites people through symbols and themes that are considered important. Art unleashes creativity and imagination. Children and teachers often rely on the arts to express feelings and thoughts. Art is often based on their experiences and represents a balance between their immediate world and their imagination. Arts can help us reflect and forge relationships with the natural world. Imagination is one of the most important aspects of learning. Utilizes common representations of subjective experiences to convey meaning. Art enables us to explore the imagination as a source of meaning, yet it is flexible, fluid and connected to our emotional self. Imagination is necessary to recreate narratives about how we can live in a sustainable future. Art can develop new cognitive patterns, develop feelings of care and interest in others. Students through art can communicate and share their experiences. Shared experiences are important for the development of identity and ecological sensitivity (York, 2014).

Art is a very creative way for children to connect with nature. It makes us susceptible to new information that is not possible to reach us through language. Art activities offer non-cognitive ways of interpreting and making meaning of experiences. Through art, the individual's ability to come in contact with the deeper levels of the soul is enhanced. It helps us to reconsider and renew the understanding of issues of our daily life. Art involves an experiential learning process. Art-based environmental education enhances students' sensitivity and helps them find new personal ways to articulate and share their environmental experiences (Boeckel, 2009).

\section{METHODOLOGY}

The research approach to environmental issues highlights the need to raise awareness of students at all levels of education, from nursery school and kindergarten to primary school, high school and university (Papavasileiou et al., 2017). Within this context, the present bibliographic research is particularly important, as it attempts to investigate qualitative and quantitative data of information and evaluations, in order to arrive - Albeit with reservations - at some answers regarding the fine arts as a pedagogical tool and the possibility of using them for environmental awareness of students.

The purpose of this scientific approach is to study research data on the possibility of utilizing fine arts for environmental awareness of students. Specifically, the possibility of utilizing fine arts is studied, in general, for the environmental awareness of students and in particular, the utilization of painting, sculpture, architecture, music and dance as well as literature, theater, cinema and photography.

The present study is a literature review (Silverman, 2010; Cohen, Manion \& Morrison, 2011; Bryman, 2016). It took place during the period January - March 2020. In this context, the systematic search and collection of valid information and data related to the pedagogical use of art for the environmental awareness of students was sought. It was considered important before starting the search of the literature on which we will rely for studying this issue, to give keywords or phrases, and simultaneously to determine the volume of information needed, as well as the type of information that will be used for the discussion of the subject.

Within this framework, the keywords "environmental education", "environmental awareness" and "fine arts" were selected. In addition, several types of art were used as keywords such as "dance", "theater", "cinema", "architecture", "literature" etc., in combination with "environmental education" and "environmental awareness". After the stage of understanding and describing the issue of this study, the selection of information sources and appropriate publication sources to be used followed. Secondary sources of 
information, such as books and journal articles, were sought. Google Scholar database was mainly used for searching the relevant publications. Emphasis was placed on scientific texts published during the last twenty years $(2000$ - 2020).

\section{RESULTS}

This literature review attempted to review research related to the role of arts in Environmental Education. The research material gathered is quite rich and interesting, however, within the context of this work will be presented only some indicative results, which demonstrate the multiple possibilities of utilizing fine arts to achieve environmental goals.

Ward (2013) argues that arts cultivate creativity and innovation. Simultaneously, they promote problem solving and support cognitive processes. They are an ideal medium to motivate non-participating students. Art-based pedagogy is argued to be a useful and creative approach to exploring and expressing an understanding of the local natural environment. Exploring the environment through art provides additional ways of getting to know and understanding the environment.

According to Ward's (2013) research, in the first phase, teachers recorded information about children's interests in the natural world and collaborated on the content of the story they would present. At the same time, they designed the space and prepared the scenery. They also chose the means of art they would use to further process the content of the story. They used movement, dramatization, music and painting activities. They also used elements of nature from their area. They also chose elements of the nature from their region. For example, they chose ribbons to represent algae. Along with the visits to nature, they activated the various art forms to reflect on the natural environment of their area. The content of the story was related to natural environment. In the second stage, the teachers searched for information about the flora and fauna of their area and transformed it creatively into stories. They linked the content of the story to the children's interests in flora and fauna, designed, collaborated and made up stories and then suggested, designed and implemented creative activities after the stories were completed. They chose the theme of the rainbow through a story where raindrops and sunbeams were the main characters.

In addition, the teachers explored the subject through various art forms, such as painting and music. The results of the research show that the themes can be rendered creatively through improvised stories that reflect what happens to children and the environment. Participating in creative art activities related to the natural world makes learning powerful and leads to changes in attitude towards the environment. Within the context of the above research, dramatization, movement, music, painting and activities with clay and generally creative activities for exploring and consolidating the concepts of the natural world were used. Children were excited by these activities.

According to Flowers (2012), children are increasingly isolated from the natural environment, as the modern way of life with the development of technology keeps children inside the house. Computer games and digital media dominate. Environmental education can help children reconnect with nature, however, these programs need to adopt effective teaching and learning methods. The integration of art activities enhances environmental education and improves students' understanding and knowledge of the environment.

The integration of art in education enhances the understanding of the subject by children through the application of art activities and the relevant experiences. Emotions guide decisions and cultivate emotional connection. When a learning experience involves emotion, the experience becomes personal, exciting, and unforgettable and at the same time the brain records the memory of the experience as more important. Art can educate children in environmental concepts.

Environmental education through art can develop awareness of environmental concepts and interaction with environmental concepts such as sustainability. Environmental education through art is a form of creativity that seeks to reconnect children with the environment and to contribute in changing attitudes and behaviors towards the environment. Art activates many senses, emphasizes social interaction and introduces new perspectives.

Within this context, literature can be used pedagogically to achieve environmental goals. There are several books with great literary stories that can contribute constructively to environmental awareness. Excellent literary texts whose environmental messages are latent in the text, although dominant, stimulating readers to elicit them, create much more stable, critical and environmentally aware readers and citizens.

Several research efforts have been made, where many literary works are presented which are proposed to be used pedagogically for the environmental awareness of students (Kanatsouli, 2005). Moreover, along with the selection of specific poems and works of prose, educational methods are proposed which are considered more experiential and can highlight the environmental dimension of literature (Tsekos et al., 2012). The 
research results from the proper use of literature are encouraging (Mc Knight, 2010; Lin et al., 2013).

Simultaneously, within the context of the creative utilization of art, the writing of stories based on the creative writing of the trainees, which has been applied in Environmental Education programs, has significant results. It involves the use of imagination, the visualization of alternative scenarios and the writing of history as a basic method.

In the study of Cunningham et al. (2003), 269 participations in a competition for writing stories for children are analyzed. The children had to imagine that they were adults and write a story about what their home and city would be like at that time. The most important issues for children as a whole were the impact of traffic, the impact of urban development on residential neighborhoods, places for children to play, the protection of the natural environment for which the city is famous, and the ability of keeping pets. More generally, the paper explores the complex problems of consulting children on strategic regional planning issues and the results of analyzing these participations in the light of these problems (Cunningham, Jones \& Dillon, 2003).

As Publicover et al. argue (2017), arts are often used to explore emotions and cultivate values on multiple issues in multiple contexts. Art, culture and education are inextricably linked to the values of a society and the quality of life. The arts have the ability to elicit emotion, encourage innovative thinking, present different perspectives, manage ambiguity, and develop cultural norms.

Music is one of the art forms that can be used in environmental education. Communication can be used as a vehicle for social change for sustainable development. Knowledge by itself does not increase environmental behavior. Emphasis is placed on the importance of emotion-based learning and the combination of pedagogical approaches to enhance environmental behavior. The processing of emotions and the cultivation of values is the strong point of the arts. With the help of art, one can reach a larger part of the population.

Music can contribute to environmental awareness either in places of formal learning or in the context of nonformal learning. A concert at a school is an example of formal learning. Songs in a camp are a form of awareness in an informal context. Informal learning can take place in any social context where music and people coexist When people delve into the work of the artists they admire, they discover environmental issues. In addition, participating in the experiences and thoughts of others through music is a form of experiential learning. The meaning and values associated with some art form may differ from the intentions of the creator and from audience to audience, which means that it is difficult to measure and predict the impact.

According to the results of the interviews with musicians in the research of Publicover et al., (2017), music is a way to send environmental messages. Music combines art and entertainment. Participants stressed that music elicits emotions whether they are positive or negative. There must be a balance between the negative and positive messages that the songs convey. Negative messages that contain the concept of threat can lead to action, however, there must be hope for outcomes. Children need to be empowered to make positive changes by developing bonds and love for the natural world.

In addition, photography, as research shows, can be used pedagogically to raise environmental awareness (Farnsworth, 2011). The ability of photography to "speak", often without words, makes it an extremely easyto-use and revealing tool, both in education and in research with children or students. Research results show that especially in Environmental Education, photography can be used in various stages of the implementation of an environmental program, sometimes as an introductory activity and sometimes as a teaching technique.

The method of utilizing photography in educational programs with children has positive results, as it contributes to the achievement of pedagogical goals, as it enriches knowledge, sensitizes students, develops their skills and cultivates environmental habits (Jena et al., 2017). The use of photographic art in the implementation of environmental programs is an excellent tool to raise students' awareness of their environment and on the other hand to acquire knowledge and skills, which arise through collaborative and collective processes. It has also been implemented with positive results in educational programs for children that participate in the design and shaping of their environment (Cosco \& Moore, 2001). Finally, photography has been used as a means of social action (Comber, Thomson \& Wells, 2001; Krieg \& Roberts, 2007).

In addition, showing a movie or an excerpt from that movie can be a powerful stimulus for discussion and further processing of the issue. It achieves this target by combining image, movement, music, speech, as well as the presentation of objects, events and natural phenomena by using visual aids. Cinema can magnify the projected objects and phenomena and contribute to the understanding of concepts, perceptions or even theoretical approaches (Skanavis, 2004).

Furthermore, the film should be used as a tool for active learning because it is a key component and 
acceptable element of everyday life (Sprau, 2001). Research shows that the effects of a movie are cognitive, emotional and sometimes behavioral in nature. The two strongest effects are related to the fact that films can allow viewers to feel important emotions and gain new perspectives on environmental issues (Temple, 2009).

The research of Janpol \& Dilts (2016) examined whether documentaries about the natural and built environment can influence environmental behaviors and perceptions. The research was conducted on psychology students. Many factors and experiences can influence people's motivation and behavior towards the built or natural environment. One of these factors is documentaries. Documentaries are a possible means of influencing people's behavior. It is a popular and important means of communication that has an impact on culture and pedagogy. In addition, they have the opportunity to articulate new ideas for environmental activism. Environmental messages reach a wider audience through documentaries. In addition, they can dispel social myths. The above research evaluated the direct effect on behavior after watching the documentary which emphasized the natural environment. Significant effects were observed on environmental perceptions which were assessed through a computer game that followed the documentary. Future research could study which features of the documentary exert influence, such as the duration of the film, the emotional content, the emphasis on visual or audio features, and other features as well.

As a pedagogical approach, film making for the environment has the potential to develop cultural and environmental literacy. Environmental literacy requires an understanding of the physical world and the development of skills and attitudes (Harness \& Drossman, 2011).

As a selected educational tool in order to achieve the desired result, which is Environmental Education, the theatrical event can be utilized, which can be included in the educational planning. Research shows that environmental drama helps learners develop communication skills, as well as the ability to collaborate and express ideas and opinions. The use of educational drama engages children emotionally in environmental issues, contributing to the achievement of pedagogical goals, in order to develop their awareness of environmental issues, to enrich their knowledge, to encourage positive attitudes and personal decisions about lifestyle and to acquire environmental action skills (McNaughton, 2004).

According to McNaughton (2010), theater as an educational tool utilizes children's natural ability to play. It is based on a story and its main feature is the improvisation. The dilemmas and problems faced by the characters create a tension. Whether in the context of dramatization, through improvisation and images, or beyond dramatization through discussion, children explore the ideas and emotions associated with these tensions and perceive different perspectives. Dramatization gives children the opportunity to function on multiple levels.

In drama, children participate on a holistic, cognitive, emotional and kinesthetic level. Dramatization activities require children to actively participate and interact with each other. The introduction of environmental and social problems or dilemmas can trigger creative individual and group responses. Dramatization allows children to visualize the places and people in the stories, to use their imagination to move into these imaginary environments, to process and interact using authentic language and behavior.

Experiential learning is a common element between dramatization and environmental education. Dramatizing and engaging in the stories of drama characters allows children to question, make judgments and choices. During the dramatization and in the activities that follow, children practice a range of skills that are considered necessary to become active citizens and take action for sustainable development.

The survey was conducted in Scotland on primary school children, aged 10-11, in urban areas. Teachers had to implement two dramatization lessons based on environmental education. The dramatization stories explored the influence of sustainable development issues of people living in imaginary communities on which the stories were based. The first story dealt with a local issue, the disposal of rubbish in an area of Scotland and the consequences for the community.

Teachers and children experienced this discomfort. They then made plans and took action to address the problem. The second issue was the destruction of tropical forests and their impact on the environment and the communities that live in the forest and are forest dependent. The subject of the dramatization was the story of a community twenty years ago whose homes were threatened by deforestation. The lessons explored the feelings and reactions of people whose lives were threatened. Teachers and children played the role of those who experienced this situation.

The results of the research showed that dramatization is a useful and effective tool for environmental education and education for sustainable development. It cultivates the attitudes and values associated with the goal of the active citizen. The dramatization gave the children the opportunity to reflect on real issues 
and problems from distance and safety of the imaginary context. Moreover, the fact that the teachers participated in their dramatization gave them the opportunity to model behavioral patterns. Improvisation enabled them to look at different perspectives and responses to environmental and sustainable development issues.

The research of Spooner et al. (2019) showed that educational theater performances at the zoo effectively provide information about knowledge regarding animals and conservation works at the zoo. The statistically significant improvement in visitors' knowledge after the show reveals that the theater is an effective means of transmitting information and knowledge. However, knowledge by itself is not enough to change behavior.

The researchers suggest that the next performances are important to include actions or goals related to emotions towards an effective Environmental Education. Their performance combined speech, songs and information on screen. The combination of these elements seemed to be effective in conveying information to the viewers. Songs make it easier to retrieve information and have a greater impact when familiar rhythms are used.

Moreover, according to Cole (2013), architectural interventions in green buildings vary from signage to interactive screens, gardens, kitchens to demonstrate some behaviors that are aimed at environmental programs for sustainable food. The above have as a result a school that supports formal environmental education, offers opportunities for non-formal education and gives students the opportunity to experience a sustainable lifestyle in their daily school life. It is hoped that these buildings will contribute effectively to the overall picture of sustainability along with curricula and formal policy.

A well-designed building can support the goals of education, the formal curriculum can motivate teachers to participate and at the same time symbolizes the school's commitment to sustainable development. Green buildings play a role in environmental education and are areas of interaction concerning environmental issues. For example, some such buildings include elements such as interaction kiosks, information signs, orchards, vegetable gardens, alternative energy systems, recycling materials and natural landscapes. Green buildings include not only the building but also the surrounding area. Indoor and outdoor spaces design aim to teach sustainability and often seeks to enhance environmental messages through building and campus design.

Space is a factor that influences learning. The disconnection between humans and nature is an obstacle to environmental education. It also matters how much time children spend in nature in order to develop environmental sensitivity and the possibility of caring for the environment later. The school building is a space for experiences that helps students learn about environmental issues through direct contact with the environment.

Student participation varies in the spectrum of person-environment interaction and interaction between individuals. The green school can be used as a tool by teachers in a formal manner and at the same time it can be used for informal learning activities, such as gardening groups that require landscaping and architectural design. Also, an important point is the harmonization of the characteristics of the school with the curriculum. The green building gives students the opportunity to be involved in the care of its components, such as the maintenance of gardens.

Inwood's (2013) research is based on the basic notion that art education can and should be used to enhance environmental literacy. The development of this form of literacy is considered essential for the continued existence of human life on the planet. It offers a dynamic way to enhance the power of environmental education by providing alternative means to expand students' environmental literacy.

Value-based art education not only helps to change attitudes, but also offers the ability to change attitudes towards the environment. By providing the means to reach students' minds and hearts, arts have the potential to be a powerful ally in environmental literacy. Art can be used effectively as a factor of social change. It is an innovative approach to the environmental problems of our society.

In Iran, research was conducted that investigated the subject of wall painting in 322 kindergartens. $27 \%$ of the issues were related to environmental concepts. In general, environmental concepts were not sufficiently included in wall painting. The question that arises is to what extent the concepts contained in wall painting can increase children's knowledge of the environment. Wall painting is considered as a means of instilling principles, concepts, thoughts and ideas and creating mental images which have a key role in social learning and shaping patterns of behavior.

One of the goals of preschool education is to raise environmental awareness. The topics with the greatest representation were the environment and its beauties (parks, forests, mountains, rivers and seas, play in nature). These topics can encourage children to love the environment. Furthermore, the subjects of the 
painting included animals from the cartoons. Topics related to environmental pollution, cleanliness and conservation of natural resources were absent. In general, the topics were assessed as repetitive and limited. No innovative themes were observed. Wall painting can be used to enhance children's awareness of environmental issues. The recording of deficiencies can be used in this direction (Meiboudi, Karimzadegan, Reza-Khalinejad, 2011).

Othman, Harun, Muda, Rashid, \& Othman (2011) in Malaysia investigated whether activities related to wall painting in schools could affect the knowledge and information of secondary school students. The research was conducted on 128 students with experimental methodology. The results of this research showed that there were statistically significant differences in the measurements related to students' environmental knowledge after the implementation of environmental activities related to wall painting in their school along with the implementation of activities in the classroom. The topic they chose was marine ecosystems.

In general, Art with its emotional power is able to stimulate the enthusiasm of students for studying environmental issues as well as expressing their environmental concerns (Dimitriou, 2009). The connection of Art and Environment is successful in the artistic movements Trash Art, Land Art, Fluxus etc. which aim at creating works from natural materials and materials treated as waste (Papavasileiou, 2015).

Trainees, either with Field Arts, such as Land Art and Earth Art, or with Arts that use waste, industrial items and all kinds of unused objects to create works of art, such as Trash Art, Cheap Art, Recycle Art etc., are guided in an artistic processing of the materials they collect from nature, as well as of the consumer goods that they themselves have taken care to collect. Research shows that learners, through art and using creative natural materials and garbage, send the message of the need to protect the environment, know alternative ways to use recyclable natural or technical materials and realize that everything around us are interrelated and useful (Yeboah et al., 2016; Baba, 2018).

\section{CONCLUSIONS}

This literature review that explored the role of fine arts in the environmental awareness of students shows that their creative use contributes to the creation of an experiential learning environment, which strengthens the emotional connection with the natural environment, the enrichment of experiences, the cultivation of feelings of care and the development of responsibility.

Within the context of the implementation of Environmental Education programs, artistic creation, in all its forms, can activate the senses, enrich students with experiences and stimuli, develop their imagination and critical thinking, give new knowledge, means of expression of emotions, perceptions and reflections. It can also enhance their creativity and develop their creative thinking.

The use of art in environmental education can contribute to the creation of a free and quality educational environment, to the development of a collaborative spirit and communication. Its importance is recognized by educators as a key way of educating and learning. Art is essential in Environmental Education, as the learners not only express themselves through art, but also discover and acquire knowledge. Thus, the artistic creations of learners, as well as the presentation of great works of art that are inspired by the environment, in the context of Environmental Education, can be a motivation for learning, can arouse the interest of students, lead to the discovery of new knowledge and become a source of information and environmental awareness.

The pedagogical use of art in environmental programs contributes to the development of self-confidence and freedom of expression. Experiencing the environment through various forms of artistic expression helps children deepen their knowledge of it and strengthen their relationship with it. Art substantially contributes to the development of children's relationship with the environment, as it cultivates through an emotional approach the familiarization and the development of a connection with space.

Literature, creative writing, painting, music, photography, dramatization, cinema, etc. - when used creatively in environmental education contribute to the externalization of the creative, expressive and artistic potential of each learner through experiential learning approaches. Artistic activities offer important creative experiences, contributing to environmental awareness and the cultivation of skills and attitudes that enable them to discover their environment. The participation in creative art activities related to the natural world makes learning stronger and leads to changes in attitude towards the environment. Simultaneously, it cultivates respect for other people, other cultures and the natural environment that promotes quality of life, contributing to building a sustainable future.

In conclusion, we would say that the utilization of fine arts in the implementation of environmental programs can make a decisive contribution to achieving environmental goals, so it is proposed to design and implement teacher training, so that, in all school programs of Environmental Education, depending on the subject, educational goals and other related scientific criteria, the possibilities provided by various art forms 
are utilized, for better quality and more effective education.

\section{REFERENCE LIST}

Baba, U. (2018). Art Work for Waste Reduction in Jos Metropolis: Prospects and Challenges. International Journal of Innovative Language, Literature \& Art Studies, 6(2), 1-8.

Boeckel (2009). Arts-based Environmental Education and the Ecological crisis: Between opening the senses and coping with psychic numbing. In Drillsma-Milgrom, B., \& Kirstina, L. (Eds.). (2009). Metamorphoses in children's literature and culture, Finland: Enostone, pp.145-164.

Bryman, A. (2016). Social research methods. (5th ed.). London: Oxford University Press.

Cohen, L., Manion, L. \& Morrison, K. (2011). Research methods in Education (7th ed.). London: Routledge.

Cole, L. (2013). The Green Building as a Medium for Environmental Education. Michigan Journal of Sustainability, 1.

Comber, B., Thomson, P. \& Wells, M. (2001). Critical literacy finds a "Place": writing and social action in a low action in a low-income Australian grade 2/3 classroom. The Elementary School Journal, 1 (4), 451-464.

Cosco, N. \& Moore, R. (2001). Our neighborhood is like that! In Chawla, L. (Ed.), Growing up in an Urbanizing World. Paris/London: Unesco/ Earthscan.

Cunningham, C. J., Jones, M. A. \& Dillon, R. (2003). Children and Urban Regional Planning: Participation in the Public Consultation Process through Story Writing, Children's Geographies, 1, (2), 201-221.

Dimitriou, A. (2009). Environmental Education: Environment, Sustainability. Theoretical and pedagogical approaches. Thessaloniki: Epikentro. (in Greek)

Farnsworth, B. E. (2011). Conservation photography as environmental education: Focus on the pedagogues. Environmental Education Research, 17(6), 769-787.

Flowers, A. (2012). The effects of an art-based environmental education program on children's environmental perceptions. Master Thesis. The University of Georgia. Athens, Georgia.

Gurevitz, R. (2000). Affective Approaches to Environmental Education: Going beyond the imagined Worlds of Childhood? Ethics, Place and Environment, 393, 253-268.

Harness H. \& Drossman H. (2011). The environmental education through filmmaking project. Environmental Education Research, 17(6), 829-849.

Inwood, H. J. (2013). Cultivating Artistic Approaches to Environmental Learning: Exploring Eco-Art Education in Elementary Classrooms. International Electronic Journal of Environmental Education, 3(2), 129-145.

Janpol, H.L. \& Dilts, R. (2016). Does viewing documentary films affect environmental perceptions and behaviors? Applied Environmental Education \& Communication, 15:1

Jena, A.K., Debnath, R., Das, J., Gupta, S. \& Bhattacharjee, S. (2017). Effects of Digital Environmental Photography and Video on the conceptual Knowledge, Skills and Eco-friendly Habits of Students. International Journal of Research in Teacher Education, 8(2), 12-27.

Kanatsouli, M. (2005). Ecology and Children's Literature, In: A.D. Georgopoulos (Ed.), Environmental Education: the new Culture which arise, pp. 535-549. Thessaloniki: University Studio Press. (in Greek)

Krieg, B. \& Roberts, M. (2007). Photovoice: insights into marginilisation through a "community lens" in Saskatchewan, Canada. In Kindon, S., Pain, R. \& Kesby, M. (Eds), Participatory Action Research Approaches and Methods, Connecting people, participation and place. London/New York: Routledge. 150-159.

Lin H.S., Hong Z.R., Chen Y.C. (2013). Exploring the development of college students' situational interest in learning science. International Journal of Science Education 35, 2152-2173.

Mc Knight, D. M. (2010). Overcoming ecophobia: fostering environmental empathy through narrative in children's science literature. Frontiers in Ecology and the Environment, 8 (6), 10-15. 
McNaughton, M. J. (2004). Educational drama in the teaching of education for sustainability. Environmental Education Research, 10(2), 139-155.

McNaughton, M. J. (2010). Educational drama in education for sustainable development: Ecopedagogy in action. Pedagogy, Culture \& Society, 18(3), 289-308.

Meiboudi, H., Karimzadegan, H., \& Reza-Khalinejad, S-M. (2011). Enhancing children's environmental awareness in kindergarten of Mashhad city using mural painting. Procedia-Social and Behavioral Science, 28, 1020-1028.

Othman, R., Harun, R., Muda, A., Rashid, N. A., \& Othman, F. Environmental Education Through Mural Painting Activities as to Enhance Secondary School Students' Knowledge and Awareness on Environment, World Applied Sciences Journal, 14, 101-106

Papavasileiou, V. (2015). Sustainable Development and Education: A multidimensional relationship. Athens: Diadrasi. (in Greek)

Papavasileiou, V., Nikolaou, E., Xanthacou,Y. Papadomarkakis, I., Matzanos, D. \& Kaila, M. (2017). Student preschool teachers' views about the pedagogical context of sustainable kindergarten. Proceedings of INTCESS 2017 4th International Conference on Education and Social Sciences. Istanbul, Turkey, 6-8 February, 2017

Publicover, J. L., Wright, T. S., Baur, S., \& Duinker, P. N. (2018). Music as a tool for environmental education and advocacy: artistic perspectives from musicians of the Playlist for the Planet. Environmental Education Research, 24(7), 925-936.

Silverman, D. (2010). Doing Qualitative Research: Issues of theory, method and practice (3 ${ }^{\text {rd }}$ ed.). London: Sage Publications.

Skanavis, K. (2004). Environment and Society. Athens: Kaleidoskopio. (in Greek)

Spooner, S. L., Jensen, E. A., Tracey, L., \& Marshall, A. R. (2019). Evaluating the impacts of theatre-based wildlife and conservation education at the zoo. Environmental Education Research, 25(8), 1231-1249.

Sprau, R. (2001). I Saw it in the Movies: Suggestions for Incorporating Film and Experiential Learning in the College History Survey Course. College Student Journal. Available http://www.findarticles.com/cf0/m0FCR/1-35/74221513/print.jhtml

Temple, L. (2009). An exploration of the role of film in environmental education. Master's thesis, Dalhousie University. Retrieved August 20, 2020 from https://www.learntechlib.org/p/126108/.

Tsekos, C., Tsekos, E. and Christoforidou, E. (2012) 'Ecology, literature and environmental education'. International Education Studies, 5(3): 187-192.

Ward, K. (2013) Creative Arts-Based Pedagogies in Early Childhood Education for Sustainability (EfS): Challenges and Possibilities, Australian Journal of Environmental Education. 29 (2), 165-181.

Wilson, C. (2011). Effective approaches to connect children with nature. Department of Conservation, Te Papa Atawhai, Wellington, New Zealand.

Wilson, J. P., \& Beard, C. (2013). Experiential learning: A handbook for education, training and coaching. Kogan Page Publishers.

Wilson, R. (2007). Nature and young children: Encouraging creative play and learning in natural environments. Routledge.

Yeboah, R., Asante, E.A., \& Opoku-Asare, N.A. (2016). Teaching Interactive Art Lessons with Recycled Waste Materials as Instructional Resources. Journal of Education and Practice, 7, 38-59.

York, R-A. (2014). Re-connecting with nature: transformative environmental education through the arts. Ph.D Thesis, Department of Curriculum, Teaching, and Learning, University of Toronto, Canada. 